\title{
The Nature of Interviewing'
}

\author{
Sandra J. Weber \\ The University of Alberta
}

\section{Interviewing: Some Critical Reflections}

Many researchers who rely heavily on open-ended, informal interviewing make only passing reference to the conception and to the lived experience of interviewing, as if interviewing were an easy-touse and uniform tool, a simple application of well-established, implicitly understood techniques. Anyone who has done a certain amount of interviewing knows that this is simply not so, but we tend to neglect this knowledge when writing our research reports. What is the interview in qualitative research? How is it lived by the researcher? How does it become "data"? How do we use, abuse, and lose our interviews? As my experience of both interviewing and of being interviewed has grown over the years, I have become more and more intrigued, even worried, by these questions. I seek here to deepen my understanding of the interview experience by describing and critically examining some of what happens before, during, and after the interview. Such an inquiry unavoidably uncovers the potential for abuse and betrayal that is inherent in the experience.

\section{The Invitation}

In reflecting on a certain phenomenon or lived experience, human science researchers often seek a new perspective by turning to others and asking, as it were, "What is your experience of the phenomenon? How do you come to see it that way?" and also, "What do you think of what I see?" In asking someone to participate in an interview, we are thus in a sense extending an invitation to conversation.

The nature and the quality of this invitation is important. The invitation may, for example, seem insincere or hollow, ringing in the participant's ears as the honeyed words of the fox trying to flatter the raven into letting go of the prized cheese. In this instance, the invitational character of the interview does not lead to a genuine conversational relation. The interviewer's real interest is in the interviewee as mere "native," "informant," or "subject," who can provide informational data to serve to substantiate an article or thesis study. If, on the other hand, the invitation is genuine, the interviewer turns to the participant as one human being to another in a way that Buber (1965) might say confirms the other-the interviewer is genuinely present, committed, and open to the participant.

Through dialogue, the interview becomes a joint reflection on a phenomenon, a deepening of experience for both interviewer and par- 
ticipant. It becomes a conversational relation between two people, one in which they come to learn as much about each other as they learn about whatever is the topic of conversation. Thus, although the honest original invitation "I would like to learn about your experience" in a sense says, "Stranger, I am interested in you-as-you because of what you-as-you reveals about human beings-as-human"; it evolves through the power of human encounter to mean, "I would like to know you and I would also like you to know me."

The interview experience holds a potential for the development of trust and commitment, and for the growth of a new human relationship, and of new or deepened understanding. But, that which makes these things possible, also holds the potential for abuse or betrayal. The interviewer's "I want to know you-as-you" may become "who cares about or notices you-as-you as long as I find out about it"; the I-Thou relationship quickly deteriorating to one of "I-It" (Buber, 1965).

In a smaller fashion, although the participant's response to the interviewer's invitation is often one of genuine commitment, saying, in effect, "I am truly here and am interested in our knowing each other," there are other possible reactions. The response, for example, might more essentially convey, "I won't really open myself to you and I don't really care to know you. I will go along with this in appearances only, because for some reason, it is to my advantage that I accept to be interviewed." Betrayal can be a two-way street.

\section{Taking a Risk}

As do all human encounters, the interview involves risk for both parties. On one hand, we run the risk of revealing that which we do not want to reveal. On the other hand, we also run the more welcome risk of gaining valuable insight into whatever it is that we discuss. One person I have interviewed put it this way:

I find it [interviewing] very hard. I think it's like taking your clothes off in public, yet there's a part of me that wants to do it because I find it very very rewarding in the sense that I can hear myself as well and maybe I can start putting together things that I didn't know I could put together.

We hear in this excerpt an important acknowledgement of the interview as a mode of learning. Through dialogue, we get to think things through, glancing at the mirror the other holds up to us, discovering not only the other, but ourselves. Although as interviewers or as participants we may sometimes fear what we or others might learn about ourselves, we may also be pleased or relieved by what we learn, relaxing and enjoying the experience, becoming less concerned about appearances and more concerned with substance, more completely involved. 
The quotation also hints at the very real risks involved in public exposure, pointing to the paradoxical nature of the interview: The interview is private and confidential, but it is also social and public. What begins as an intimate conversation between two people may soon find its way into the public arena. The risk of exposure, however, and the call to commit one's oral discourse in an exceptional way is often one-sided in the interview situation, both the researcher and the participant knowing full well that the focus of analysis will be on what the participant says, not on the fumbling words of the interviewer. This, perhaps, is the heart of the potential unfairness of the interview experience. What the researcher says does not often show up in print for the world to see. As long as it is the researcher who records, asks the questions, and decides how to deal with the interview material, the balance of power usually remains firmly in his or her hands.

\section{The Element of Trust}

In accepting the interviewer's invitation to conversation, the participant is thus showing great trust and hope: hope that what will be discovered will be "good"; hope that the interviewer will be faithful to the experience and to the participant, not misinterpreting, misrepresenting, or distorting the participant's meaning and intentions, not revealing publically that which by its very nature should remain private; in other words, not betraying the trust displayed in accepting the invitation. Why do so many show a willingness to be interviewed in spite of such risk? Perhaps one accepts to be interviewed because in the very invitation there is a sense of trust and a confirmation of the participant as a human being of importance, as someone who knows something of value, to research and science. Perhaps one accepts because for both the participant and the interviewer, the interview offers the opportunity to be known, to gain self-understanding, to give something to the other, as well as a chance to delight in the intersubjective nature of human understanding. Perhaps one accepts because to trust that "this other will not exploit me" is part of what it means to be human.

\section{Beyond Preconception}

In our society, interviewing is often associated with intrusive journalism, with job-hunting, or with the manipulative paradigm of experimental psychology. The interviewer may be perceived as the one who controls the situation, who is "in the know," who asks all the questions, and who influences how we appear and in a sense, who we become. Interviewing may sometimes be perceived as exploitation or as a game in which one person is out to trick the other into revealing that which should not be revealed. The object of the game for the person being interviewed may thus become concealment, the control of appearances; in other words, the very opposite of what the researcher seeks: 
Human beings, as Buber points out ... know how to shut others out; they know how not to reveal themselves to the other. This is especially true when they are confronted with someone who wants to see what makes them "tick." (Friedman, 1983, p. 174)

The perceptions and preconceptions we have of the interview experience can greatly influence or shape the relationship between participant and interviewer, even outside the interview situation. We sometimes find it difficult to acknowledge interviewing as an integral part of our everyday experience and not some artificial thing outside of it. For example, to my astonishment, a participant with whom I feel at ease and whom I greatly respect was suddenly on her best behavior with me, not quite able to forget my research interest in her, saying, "I do feel examined and even when we're not interviewing, I think it is coloring our relationship." It was only then that I realized that I too had changed in the way I related to her, that interviewing is not something I could easily switch on and off but rather a mode of being that needs to be questioned.

Perhaps we need to go beyond the everyday notions of interviewing to its earlier meaning of "seeing the between" (entre vue) or meeting to share a viewpoint. As Martin Buber (1966) and Maurice Friedman (1983) remind us, it is the "between" (entre) that reveals, that permits understanding. It is through the seeing of that which is neither only you nor only $I$ but is rather our between that we learn about each other. If it is to be more than a game of concealment, the interview must be a conversation between interviewer and participant that evokes the participant's lived experience, seeking shared understanding. Such meetings structure themselves in the talking, generating questions and possible interpretations for both people. As anthropologist Miles Richardson (1974) suggests, the participant becomes in a sense the teacher, the one whose job is to teach this stranger what he or she knows.

This active role given to the participant does not imply an abdication of responsibility on the part of the researcher; it implies, rather, an attitude of respect for the participant; it implies an openness and a willingness to learn. The openness of questioning, however, is never absolute because a question always has a certain direction. As Heidegger (1969, p. 269) has asserted, "the very act of posing a question is disclosure, for to question is to sketch in advance the context of meaning in which a particular inquiry will move." The answering in turn invites more questioning, also guiding the interview. The interview is thus shaped by both people, becoming, for the moment, their shared abode.

The interview is a special instance of human dialogue. Because the focus is ostensibly on the participant's experience, the interviewer might at first say very little, enjoining the dialogue with the mean- 
ingful silence of listening and thinking, participating at times more through gesture than speech. As in all conversations, during the interview we often experience moments of judgment and of emotional reaction, silent reactions such as "what a wonderful person," "what a funny thing to say," or "how interesting." Other thoughts that greatly contribute to the hermeneutic nature of the interview are those thoughts relating the other's experience and ideas to our own. "I know how she feels, that happened to me, too"; "how different from my own experience"; or, "that's how I see it, too." These feelings and thoughts, though often unspoken and sometimes denied, form a part of the silent or hidden dialogue of the interview. We cannot and should not be unaffected by what is said, unless of course we are either not listening or are simply denying what we feel under the false and smug cloak of scientific objectivity. Having thoughts and feelings about a person is not a betrayal of what it means to be either an interviewer or a participant: On the contrary, it is only in relating to the other as one human being to another that interviewing is really possible.

The interview has its best moments when the interviewer and the parlicipanl are both caught up in the phenomenon being discussed, when both are trying and wanting to understand. At these times, both people forget the tape-recorder, forget that "this is an interview," and simply talk and listen in a genuine dialogue that is focussed on the phenomenon in question. They are talking to each other rather than past each other. The interviews, then, are very much a shared experience affecting both.

\section{Remembering People}

Interviews can continue long after the people we interview have departed. For example, the words of my participants and their presence often linger as I find myself recalling and reflecting on shared moments. My solitary interrogation of their being continues intermittently and at odd moments. In the middle of my grocery shopping or other chores, for example, I may find myself thinking of questions I wish to ask them, of things I wish to know. Some interviews never end. The time they inhabit goes far beyond the clock time of the starting and the stopping of the tape recorder or the meeting and the parting of two people.

A dialogue between two people may evolve into a conversation between three or more people. I often find myself, for example, questioning one participant in the light of what another person has said, or exclaiming in silent surprise when one participant contradicts or echoes the thoughts of another. Through me, the ideas of participants are exchanged, challenged, tested.

Unfortunately, in our haste to publish, to analyze, and to write, we may forget our commitment and responsibility as human beings, 
turning the interview into "data," overlooking or destroying the experience of its very creation as we jump immediately to typed transcripts, substituting without hesitation the printed word for the lived experience. We tend to ignore the words of the researcher, as if they have nothing to reveal. Through analysis and writing, interviewers often detach themselves from the original experience, disowning in a sense their own part, feigning a neutrality which betrays the interview; turning, as it were, to the person with whom they have shared an experience and are denying more than a catalytic role for what was said. The interview becomes a dessicated transcript unable to evoke the originating experience.

We tend to focus our analysis on what was said, forgetting or neglecting how what was said made sense. As Barritt (1984) points out:

Writing and speaking are quite different experiences. They are made to appear translations of one another only by overlooking the ordinary facts and focusing on the extraordinary.... From a descriptive-phenomenological view, it seems remarkable that anyone should expect them to be alike. (p. 132)

By its very nature, written material usually differs from the oral discourse of an interview. Written accounts are often more polished, coherent, and selective than the more tentative, rambling nature of conversation. In a certain way, written accounts may seem more thoughtful, offering the insightful reflection afforded by the time to think and to choose one's words.

It is, however, the conversation within the interview that is more evocative of lived experience. In conversation, the words almost seem to choose their speaker, offering a direct access to experience, revealing a complexity of reactions, feelings, and thoughts. The rapid outpouring of our words escapes the track we set it, revealing ambiguities, confusion, variety, and paradox, offering an authentic mosaic of perceptions and thoughts, and providing a sort of window to consciousness. The expression "just thinking aloud" suggests the intimacy and the unfinished nature of oral language, which, of course, is precisely why it can be so revealing, and why we seek to interview people.

\section{The Betrayal}

An interview can never be simply conversation by the very fact that it is usually recorded and transcribed, and invariably written down. An interview becomes the spoken word captured with the same permanence as a written document. There is a certain paradox and possibility of betrayal here. The participants are implicitly asked to allow their spontaneous, tentative, oral language to be treated as written language, their words committing them to paper for the world to see. By contrast, when I am writing I may not know what I 
am going to write until I have put pen to paper, but I do have the chance to examine what I have just written, decide how to improve it, and to consider whether or not I want to share it. These choices are not usually afforded by the riskier oral discourse of the interview. As a person being interviewed, I can modify and amplify what I have said, but I cannot change the fact that you, the interviewer, have heard me say it and will capture it on paper if you so choose. Moreover, if I were to write about what I have just spoken about, it would be more than a mere transcription of my talking.

Writing down verbatim someone's oral language transforms that language, robbing it at times of its power, clarity, and depth, even its meaning. Verbatim transcription makes little accommodation for tone of voice and emphasis, and little accommodation for the differences in style, words, and form that exists between oral and written modes of communication. As Merleau-Ponty (1964) has suggested, any merely mechanical attempt to "capture" experience is fraught with difficulties:

It is said that the exact recording of a conversation which had seemed brilliant later gives the impression of indigence. The presence of those who were speaking, the gestures, the physiognomies, and the feeling of an event ... are all lacking in the recording. Henceforth the conversation no longer exists: it IS, flattened out in the unique dimension of sound and all the more deceptive because this wholly auditory medium is that of a text read. (p. 57)

What is the researcher's responsibility here? Should not fidelity to the participants' meaning and to the interview experience take precedence over endless verbatim quotes? Is not part of the research task to make meaning clear, that is, to remain true to the original aural experience as much as possible? Perhaps the tape recordings combined with written transcripts and notes should be considered the data of preference for analysis. For some interviewers, listening to the tapes helps recapture the tone of voice, the twinkling to the eyes, the pained expression, the cluttered desk, the laughter, the leaning forward, all the things that are lost in a written transcript. This spoken word can be more evocative, more suggestive of the lived experience to which we wish to remain close.

The potential for the abuse and betrayal in the interview experience is at the same time a potential for developing trust and shared understanding. Which potential is fulfilled might depend on the nature of the particular interview experience itself, on the nature of the relationship between interviewer and participant, on the preconceptions and power relations they bring to the interview, and on what happens after the interview is over, when the researcher decides how to deal with the experience. As Breed (1983) wrote: 
the requirements of our impulse to codify and our professional need to publish and present will always complicate the human dignity celebrated by human science research; the question for us then is with what grace and modesty [and, I would add, justice] we handle the complications. (p. 4)

\section{Note}

1. This paper was presented at the International Human Science Research Conference, The University of Alberta, May, 1985.

\section{References}

Barritt, L. (1984). Writing/speaking: A descriptive phenomenological view. In B. Kroll \& R. Vann (Eds.), Exploring speaking-writing relationships (pp. 124-133). Urbana, IL: National Council of Teachers in English.

Breed, C. (1983). Folk, wisdom, and hindsight. The Human Science Newsletter. Phenomenology Seminar, School of Education, University of Michigan.

Buber, M. (1965). Between man and man. (R. Gregor Smith, Trans.). New York: Macmillan.

Buber, M. (1966). The knowledge of man: A philosophy of the interhuman, M. Friedman (Ed.). New York: Harper Torchbooks.

Erikson, F. (1973). Some approaches to inquiry in school-community ethnography. Anthropology and Education Quarterly, 4(2).

Friedman, M. (1983). The confirmation of otherness in family, community, and society. New York: Pilgrim.

Heidegger, M. (1969). In W.H. Bossart, Three directions of phenomenology. In M. Greene (Ed.), The anatomy of knowledge. Amherst: University of Massachussets Press.

Merleau-Ponty, M. (1964). Signs. Evanston: Northwestern University Press.

Richardson M. (1974). Anthropologist-The myth teller. American Ethnologist, 517-530. 